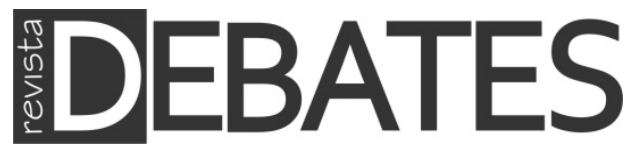

\title{
Una nueva forma de medir la calidad de la democracia: la democracia legal o constitucional
}

\author{
A new way to measure the democracy's quality: a legacy or \\ constitutional democracy
}

\section{Manuel Ángel Rodríguez Edeza Jorge Giménez Patricia Rocha Thiago Engelman Leonardo de Alancaster}

\section{Resumen}

El proyecto plantea una nueva forma para medir la calidad de la democracia: desde los textos constitucionales. Se considera que si se habrá de medir la posibilidad de la democracia, sobre todo en regímenes en desarrollo, se tendrá que empezar por analizar sus textos constitucionales sea por una cuestión legal, como por una cuestión ideal de democracia, en tanto naciones distintas, multiétnicas y multiculturales. En ese sentido, se abre otra discusión, si debemos referirnos a la democracia en singular (como un ideal) o las democracias (en plural) particulares. Toma como soporte teórico los elementos o dimensiones que Morlino (2008) y Alcántara (2008) consideran primordiales para la democracia y los busca y compara con los textos constitucionales de Brasil, Argentina, México, Paraguay y Uruguay. Al final se advierte que, sea para mejorar la democracia de los países en cuestión, como para buscar un ideal democrático, se deberán adecuar los textos constitucionales.

\section{Palabras clave}

Democracia; Democracias; Constituciones; Democracia Constitucional.

\begin{abstract}
The project proposes a new way to measure the quality of democracy: from the constitutional frameworks. It is considered that if the possibility of democracy, especially in regimes under development, is to be measured, it will be necessary to begin by analyzing its constitutional frameworks by a legal question, as by an ideal question of democracy, as nations different, multiethnic and multicultural. In that sense, another discussion opens, whether, we should refer to democracy in single (as an ideal) or the democracies (in plural). It takes as theoretical support the elements or dimensions that Morlino (2008) and Alcántara (2008) consider primordial for democracy and seeks and compares with the constitutional texts of Brazil, Argentina, Mexico, Paraguay and Uruguay. In the end it is warned that, in order to improve the democracy of the countries in question, and to seek a democratic ideal, the constitutional texts must be adapted.
\end{abstract}

\section{Keywords}

Democracy; Democracies; Constitutions; Constitutional Democracy. 


\section{Introducción}

A poco más de una década, las discusiones sobre la democracia han superado de algún modo el aspecto procedimental para buscar las cuestiones sustantivas (BARREDA, 2010; GILAS, 2012) y productivas. Es decir, se trata no solo de llegar a ella, sino que produzca y rinda frutos, de ahí, que hablar de la calidad de la democracia (o de las democracias), sea en la actualidad lo más propicio y adecuado (DIAMOND y MORLINO, 2004; ALCÁNTARA, 2008; MORLINO, 2008; TOVAR, 2010; BARREDA, 2010).

No obstante, esta pretensión no ha sido homogéneamente considerada; hay quienes se resisten ver a la democracia como algo más que el elegir y generar gobiernos de forma justa y adecuada, aunque ajenos a lo que éstos entreguen en su actuar eso, no es asunto de la democracia, señalan (CORBETTA y PEREZ-LIÑAN, 2001; LEVINE y MOLINA, 2007).

Y aunque esta discusión no ha sido del todo superada, se han considerado algunos índices para medirla entre los principales, el Freedom House Index (FHI), el Índice de Desarrollo Democrático (IDD) de la Fundación Konrad Adenauer, el de la Unidad de Inteligencia Económica de The Economist Group (EIU, por sus siglas en Inglés) y el construido por Levine y Molina (2007, p. 18-46), por mencionar algunos, en su trabajo "la calidad de la democracia en América Latina: una visión comparada".

En ese orden de ideas, se pretende advertir sobre la necesidad de referenciar los entramados constitucionales o constituciones, en tanto son naciones distintas, multiétnicas y multiculturales, aunque ciertamente, hay voces que opinan lo contrario (DIAMOND, 2015).

Nuestro principal planteamiento, es que la democracia referencia algo, no es un concepto vacío sino que contiene elementos descriptibles y medibles. El segundo, que no es algo único y acabado, sino que comprende naciones; ciertamente se podría analizar también en sentido ideal o general, no obstante, consideramos esta forma solo referencial.

Bajo estas consideraciones, se propone que se puede medir de dos formas: de manera vertical y horizontal. La primera, en tanto una misma, en relación a un ideal o idea general de democracia; la segunda, en comparación con otras. La democracia, y las democracias.

Consideramos como una primera discusión y/o confusión, querer medir la democracia y a las democracias de manera igual u homologada, con índices inclusive, que no fueron creados expresamente para ello, no obstante que, la y las democracias pueden responder a distintos momentos y escenarios, ciertamente, Morlino (2008) y 
Alcántara (2008) establecen situaciones generales de medición, los procedimientos, el contenido y los resultados, con sus respectivas dimensiones (ver MORLINO, 2008; ALCÁNTARA, 2008), sin embargo, aún con ello, es necesario advertir cuestiones particulares de los casos: contextos y peculiaridades: las distintas naciones democráticas.

Así, la democracia es un proceso de distintos niveles y características, no finito y acabado, pero lo que es más, pudiendo graduarse y degradarse. Las naciones que hoy están en democracia, pudieran no estarlo mañana o en un piso menor y viceversa. De ahí, que lo que se propone es partir de los marcos en los cuales se desenvuelven las democracias, no solo culturales, espaciales e históricos (GONZÁLEZ y EDEZA, 2016), sino constitucionale y legales, como un crisol de tales aspectos.

La discusión se desenvuelve a veces alejada de tal situación, como si todas las naciones compartieran (o debieran compartir) la misma historia, las mismas leyes y las mismas características. Ciertamente, es atrayente analizar la democracia en un sentido ideal, pero las democracias se deben analizar en contextos reales y correspondientes.

Intentar juntar a ambas, no nos aleja de una, pero él no estar totalmente correspondidas no lo hace tampoco. En todo caso ¿Qué tan democráticas son nuestras democracias? $\mathrm{O}$, ¿Qué tan democráticas son nuestras constituciones? Y nos referimos a ello, porque si las vamos a cambiar o modificar (a las democracias), al menos tendríamos que considerarlo.

En este orden de ideas, aprovechando las dimensiones seńaladas por Morlino (2008) y Alcántara (2008), habrá que ver los marcos constitucionales (donde existen y construirlos donde no los hay) y compararlos; hasta dónde nuestras democracias responden a tales dimensiones, como un elemento crucial en el análisis, no para acercarlos al ideal democrático solo, sino para observar que tanto se acercan a nuestra realidad y, en todo caso, adaptarlos y mejorarlos, sino, no avanzaremos. Para hablar de democracia, desafortunada o afortunadamente, tenemos que hablar de cuestiones legales.

\section{Índices $y$ comparación de sus resultados vs los paises analizados}

De acuerdo con los resultados y análisis de los 4 índices considerados, las democracias no varían mucho en su comparación final y valoración en los países analizados (ver tablas). De hecho, si consideramos simple y llanamente mediciones de 
64 | Manuel Edeza, Jorge Giménez, Patricia Rocha, Thiago Engelman e Leonardo de Alancaster

alta, media y baja (Tabla 1) y/o mediciones ponderadas en cada uno de los índices (Tabla 2), los países analizados prácticamente permanecen igual. En la suma el más alto sigue siendo Uruguay, seguido de Argentina, Brasil y/o México y Paraguay, en ese orden. El único que modifica un tanto más sustancial dicha clasificación es el IDD (Índice de Desarrollo Democrático), donde Brasil es colocado último lugar. Más esto qué significa? Que su democracia, o las democracias de quienes aparecen abajo son deficientes en realidad?

Lo que nos lleva a buscar algo más o quizás a preguntar, como Levine y Molina (2007), si estaremos midiendo bien las democracias (así, en plural); basándonos más en el buen gobierno que en la democracia per se.

Tabla 1 - Índices y comparación de sus resultados vs los países analizados

\begin{tabular}{|c|c|c|c|c|c|}
\hline Pais/Parametro & Uruguay & Argentina & Brasil & Mexico & Paraguay \\
\hline FH alto & $\mathrm{X}$ & $\mathrm{X}$ & $\mathrm{X}$ & & \\
\hline FH medio & & & & $\mathrm{X}$ & $\mathrm{X}$ \\
\hline \multicolumn{6}{|l|}{ FH bajo } \\
\hline IDD alto & $\mathrm{X}$ & & & & \\
\hline IDD medio & & $\mathrm{X}$ & & $\mathrm{X}$ & \\
\hline IDD bajo & & & $\mathrm{X}$ & & $\mathrm{X}$ \\
\hline EIU alto & $\mathrm{X}$ & $\mathrm{X}$ & $\mathrm{X}$ & & \\
\hline EIU medio & & & & $\mathrm{X}$ & $\mathrm{X}$ \\
\hline \multicolumn{6}{|l|}{ EIU bajo } \\
\hline LM alto & $\mathrm{X}$ & $\mathrm{X}$ & $\mathrm{X}$ & $\mathrm{X}$ & $\mathrm{X}$ \\
\hline \multicolumn{6}{|l|}{ LM medio } \\
\hline LM bajo & & & & & \\
\hline
\end{tabular}

Fuente: FH (FREDOM HOUSE, 2017), IDD (ÍNDICE DE DESARROLLO DEMOCRÁTICO, 2017), EIU (ÍNDICE DE DESARROLLO, 2017) y LM (LEVINE y MOLINA, 2007).

Tabla 2 - Índices sobre calidad de la democracia 2016 evaluaciones ponderadas

\begin{tabular}{l|l|l|l|l}
\hline Indices & FH & IDD & EIU & LM $^{*}$ \\
\hline Brasil & $2.0 / 79$ pts. (3) & $2,776(5)$ & $6.90(3)$ & $76.4(4)$ \\
\hline Argentina & $2.0 / 82$ pts. (2) & $5,159(2)$ & $6.96(2)$ & $82.9(2)$ \\
\hline Mexico & $3.0 / 65$ pts. (4) & $4,454(3)$ & $6.47(4)$ & $82.5(3)$ \\
\hline Uruguay & $1.0 / 98$ pts. (1) & $9,353(1)$ & $8.17(1)$ & $93.7(1)$ \\
\hline Paraguay & $3.0 / 64$ pts. (5) & $3,251(4)$ & $6.27(5)$ & $69.8(5)$ \\
\hline
\end{tabular}

FH (Freedom House Índex)- La mejor puntuación es 1 (o 100 puntos) y la peor 7 (o 0 puntos). IDD (Índice de Desarrollo Democrático)- La máxima puntuación posible son 10,000 puntos. EIU (Economist Intelligence Unit)- La mejor puntuación es 10. LyM* (Levine, Daniel y Molina, Enrique)La mejor puntuación es 100. Los datos corresponden a 2007 ( ) Los paréntises contienen el lugar de colocación entre los países analizados. 
Fuente: FH (FREDOM HOUSE, 2017), IDD (ÍNDICE DE DESARROLLO DEMOCRÁTICO, 2017), EIU (ÍNDICE DE DESARROLLO, 2017) y LM (LEVINE y MOLINA, 2007).

\section{Morlino y Alcántara}

Para Morlino (2008) y Alcántara (2008), la democracia puede ser medida en su calidad en tres segmentos diferenciados, el procedimiento, el contenido y los resultados considerando 8 dimensiones:

Estado de derecho o imperio de la ley, refieren a esta dimensión como la base de todas las demás; el imperio de la ley o regla de la ley, es aquella donde todos los ciudadanos son iguales ante la ley, la cual es confiable, consistente y aplicada por un poder judicial independiente.

Participación, un régimen puede ser democrático, señalan, sólo si garantiza los mecanismos para la participación política y los derechos de todos los ciudadanos en edad de participar. No sólo votando, sino en todas las formas legales de participación. Competencia, normal, libre y confiable para todos los partidos políticos; con reglas que satisfagan su lucha legítima por el poder; electoral, en los medios de información y el financiamiento.

Rendición de cuentas vertical, la posibilidad de que el electorado pueda sancionar a su autoridad depende de la información, la justificación y la pena a esa actuación; generalmente es en la elección donde esa accontability se concretiza, no obstante, la transparencia y rendición de cuentas, son mecanismos que pueden ayudar a ese proceso, algunas otras formas de democracia directa podrían también ser consideradas.

Rendición de cuentas horizontal, pero la rendición de cuentas no sólo debe ser con el ciudadano dicen; mecanismos interinstitucionales entre poderes e instancias deben ser creados para mantener "balances y contrapesos" y una transparencia en la actuación y rendición de cuentas de y entre instituciones, dar seguimiento y fiscalizar su operación.

Libertad, consistente básicamente en tres tipos de derechos: políticos, civiles y sociales. Políticos, para votar, para elegir y ser elegido. Civiles para las libertades de ideología, expresión, información, religión, organización y asociación y sociales o económicas sociales, no sólo para la propiedad privada, sino el empleo y la negociación.

Igualdad, en esa libertad y esos derechos. La igualdad política y legal de todos sus ciudadanos. No necesariamente material o económica, sino sustantiva, esto es de posibilidades. 
Resposiveness, o resultados de satisfacción con la democracia y su legitimación.

En ese contexto, una de nuestras primeras consideraciones, será medir entonces esa posibilidad democrática; se está de acuerdo, que aún en la aceptación de la misma, existen marcos constitucionales que la garantizan o debieran garantizar o posibilitar; ¿Qué tanto los marcos constitucionales de Brasil, Argentina, México, Paraguay y Uruguay, están preparados para ello? ¿Qué tanto representan el ideal democrático y su posibilidad, o debieran adaptarse? Después de todo, la democracia tiene que ser legal.

\section{Comparación calidad democrática constitucional}

\section{Brasil}

\section{Antecedentes}

La Constitución de la República Federativa de Brasil 1988, fue aprobada por la Asamblea Nacional Constituyente el 22 de Septiembre de 1988 e promulgada el 5 de octubre del mismo año; tiene 250 artículos, siendo la séptima Constitución de Brasil.

Cuadro 1 - Comparativo Brasil

\begin{tabular}{|c|c|c|}
\hline Pais/ Variable & Brasil & Observaciones \\
\hline Procedimiento & Constitución & Comentarios \\
\hline Estado de derecho & $\begin{array}{l}\text { Artículo 1. La República Federativa del Brasil, se constituye en } \\
\text { Estado Democrático de Derecho. Todo el poder emana del pueblo, } \\
\text { que lo ejerce por medio de representantes electos o directamente, en } \\
\text { los términos de esta Constitución. } \\
\text { Artículo 101. Los Ministros del Supremo Tribunal Federal serán } \\
\text { nombrados por el Presidente de la República, después de aprobada la } \\
\text { elección por la mayoría absoluta del Senado Federal. }\end{array}$ & $\begin{array}{l}\text { Existe estado de } \\
\text { derecho }\end{array}$ \\
\hline Participación & $\begin{array}{l}\text { Artículo 14. La soberanía popular será ejercida por el sufragio } \\
\text { universal y por el voto directo y secreto, con valor igual para todos, y, } \\
\text { en los términos de la ley, mediante: I - plebiscito; II - referéndum; III } \\
\text { - iniciativa popular. } \\
₫ 1^{\circ} \text { El alistamiento electoral y el voto son: I - obligatorios para los } \\
\text { mayores de dieciocho años; II - facultativos para: a) los analfabetos; b) } \\
\text { los mayores de setenta años; c) los mayores de dieciséis y menores de } \\
\text { dieciocho años. }\end{array}$ & $\begin{array}{l}\text { Hay participación } \\
\text { electoral } \\
\text { obligatoria } \\
\text { mecanismos } \\
\text { directos } \\
\text { participación }\end{array}$ \\
\hline $\begin{array}{c}\text { Competencia } \\
\text { partidaria }\end{array}$ & $\begin{array}{l}\text { Artículo } 17 \text {. Es libre la creación, fusión, incorporación y extinción de } \\
\text { partidos políticos, resguardados a la soberanía nacional, el régimen } \\
\text { democrático, el pluripartidismo, los derechos fundamentales de la } \\
\text { persona humana y observados los siguientes preceptos: ... }\end{array}$ & $\begin{array}{l}\text { Existe posibilidad } \\
\text { de competencia } \\
\text { partidaria }\end{array}$ \\
\hline
\end{tabular}




\begin{tabular}{|c|c|c|}
\hline & $\begin{array}{l}\$ 3^{\circ} \text { Los partidos políticos tienen derecho a recursos del fondo } \\
\text { partidista y acceso gratuito a la radio ya la televisión, en la forma de la } \\
\text { ley. } \\
\$ 4^{\circ} \text { Está prohibida la utilización por los partidos políticos de } \\
\text { organización paramilitar. }\end{array}$ & \\
\hline $\begin{array}{l}\text { Rendición de } \\
\text { cuentas electoral } \\
\text { (vertical) }\end{array}$ & $\begin{array}{l}\text { Artículo 44. El Poder Legislativo es ejercido por el Congreso } \\
\text { Nacional, que se compone de la Cámara de Diputados y del Senado } \\
\text { Federal. La Cámara de Diputados tendrá una duración de cuatro años. } \\
\text { Artículo 46. El Senado se compone de representantes de los Estados y } \\
\text { del Distrito Federal, elegidos según el principio mayoritario. Con un } \\
\text { mandato de ocho ańos. } \\
\text { Artículo 76. El Poder Ejecutivo es ejercido por el Presidente de la } \\
\text { República, con mandato de cuatro ańos y posibilidad de reelección. }\end{array}$ & $\begin{array}{l}\text { Hay elecciones } \\
\text { recurrentes }\end{array}$ \\
\hline $\begin{array}{l}\text { Rendición de } \\
\text { cuentas } \\
\text { interinstitucional } \\
\text { (horizontal) }\end{array}$ & $\begin{array}{l}\text { Artículo } 2^{\circ} \text {. Son Poderes de la Unión, independientes y armónicos } \\
\text { entre sí, el Legislativo, el Ejecutivo y el Poder Judicial. } \\
\text { Artículo 18. La organización político-administrativa de la República } \\
\text { Federativa del Brasil comprende la Unión, los Estados, el Distrito } \\
\text { Federal y los Municipios, todos autónomos, en los términos de esta } \\
\text { Constitución. } \\
\text { Artículo 70. La fiscalización, financiera, presupuestaria, operativa y } \\
\text { patrimonial de la Unión y de las entidades de la administración, en } \\
\text { cuanto a la legalidad, legitimidad, economía, aplicación de las } \\
\text { subvenciones y renuncia de ingresos, será ejercida por el Congreso } \\
\text { Nacional, mediante control externo y sistema de control interno de } \\
\text { cada Poder. } \\
\text { Artículo } 71 \text {. El control externo, a cargo del Congreso Nacional, será } \\
\text { ejercido con la ayuda del Tribunal de Cuentas de la Unión. } \\
\text { Artículo 73. El Tribunal de Cuentas de la Unión, integrado por } \\
\text { nueve Ministros, tiene sede en el Distrito Federal, cuadro propio de } \\
\text { personal y jurisdicción en todo el territorio nacional, ejerciendo, en lo } \\
\text { que corresponda, las atribuciones previstas en el art. } 96 \text {. } \\
\text { Artículo } 74 \text {. Los Poderes Legislativo, Ejecutivo y Judicial } \\
\text { mantendrán, de forma integrada, sistema de control interno. } \\
\text { Artículo 127. El Ministerio Público es una institución permanente, } \\
\text { esencial a la función jurisdiccional del Estado, encomendándole la } \\
\text { defensa del orden jurídico, del régimen democrático y de los intereses } \\
\text { sociales e individuales indisponibles. } \\
\text { Artículo 134. La Defensoría Pública es una institución permanente, } \\
\text { esencial a la función jurisdiccional del Estado, incumbiendo, como } \\
\text { expresión e instrumento del régimen democrático, fundamentalmente, } \\
\text { la orientación jurídica, la promoción de los derechos humanos y la } \\
\text { defensa, en todos los grados, judicial y extrajudicial, de los derechos } \\
\text { individuales y colectivos, de forma integral y gratuita, a los necesitados } \\
\ldots \\
\text { Ley n. 12.846. Ley Anticorrupción Brasileña } \\
\text { Artículo 1o. Esta Ley dispone sobre la responsabilización objetiva } \\
\text { administrativa y civil de personas jurídicas por la práctica de actos }\end{array}$ & $\begin{array}{l}\text { Existen pesos y } \\
\text { contrapesos }\end{array}$ \\
\hline
\end{tabular}


68 | Manuel Edeza, Jorge Giménez, Patricia Rocha, Thiago Engelman e Leonardo de Alancaster

\begin{tabular}{|c|c|c|}
\hline & contra la administración pública. & \\
\hline Contenido & Constitución & Comentarios \\
\hline Libertad & $\begin{array}{l}\text { Artículo } 5^{\circ} \text {. IV. Es libre la manifestación del pensamiento, siendo } \\
\text { vedado el anonimato. } \\
\text { Artículo } 8^{\circ} \text {. Es libre la asociación profesional o sindical. } \\
\text { Artículo } 9^{\circ} \text {. Se garantiza el derecho de huelga. }\end{array}$ & $\begin{array}{l}\text { Hay libertad en la } \\
\text { ley }\end{array}$ \\
\hline Igualdad & $\begin{array}{l}\text { Artículo } 3^{\circ} \text {. Constituyen objetivos fundamentales de la República } \\
\text { Federativa del Brasil: I - construir una sociedad libre, justa y solidaria; } \\
\text { II - garantizar el desarrollo nacional; III - erradicar la pobreza y la } \\
\text { marginación y reducir las desigualdades sociales y regionales; IV - } \\
\text { promover el bien de todos, sin prejuicios de origen, raza, sexo, color, } \\
\text { edad y cualquier otra forma de discriminación. } \\
\text { Artículo } 5^{\circ} \text {. Todos son iguales ante la ley, sin distinción de ninguna } \\
\text { naturaleza. }\end{array}$ & $\begin{array}{l}\text { Hay igualdad en } \\
\text { la ley }\end{array}$ \\
\hline Resultado & Constitución & Comentarios \\
\hline $\begin{array}{c}\text { Respuesta } \\
\text { (Responsiveness) }\end{array}$ & $\begin{array}{l}\text { Artículo } 5^{\circ} \text {. LXXIV. El Estado prestará asistencia jurídica integral y } \\
\text { gratuita a los que demuestren insuficiencia de recursos. } \\
\text { Artículo. 6o. Los derechos sociales a la educación, la salud, la } \\
\text { alimentación, el trabajo, la vivienda, el transporte, el ocio, la } \\
\text { seguridad, la seguridad social, la protección a la maternidad y la } \\
\text { infancia, la asistencia a los desamparados. }\end{array}$ & $\begin{array}{l}\text { Hay resultados } \\
\text { aparentes }\end{array}$ \\
\hline
\end{tabular}

Fuente: Brasil (1988).

\section{Conclusión}

La Constitución Federativa de Brasil, deja en claro que contiene los elementos básicos de democracia considerados por Morlino (2008) y Alcántara (2008). Lo que se puede resaltar es su composición ejecutiva, con Presidente y Vicepresidente, además de la consideración de reelección para ambas posiciones.

\section{Argentina}

\section{Antecedentes}

La Constitución Nacional de la Nación Argentina, fue aprobada inicialmente por una asamblea constituyente integrada por representantes de trece provincias en la ciudad de Santa Fe en el año 1853. Los diferentes textos de esta Constitución han sido reformados siete veces, siendo la última en 1994, y han sido dejados sin efecto o modificados por autoridades de facto en nueve oportunidades. Contiene 129 artículos y 17 disposiciones transitorias. 
Cuadro 2 - Comparativo Argentina

\begin{tabular}{|c|c|c|}
\hline Pais/ Variable & Argentina & Observaciones \\
\hline Procedimiento & Constitución & Comentarios \\
\hline $\begin{array}{l}\text { Estado de } \\
\text { derecho }\end{array}$ & $\begin{array}{l}\text { Artículo 36. Esta Constitución mantendrá su imperio aun cuando se } \\
\text { interrumpiere su observancia por actos de fuerza contra el orden } \\
\text { institucional y el sistema democrático. Estos actos serán } \\
\text { insanablemente nulos... } \\
\text { Artículo 18. Ningún habitante de la Nación puede ser penado sin } \\
\text { juicio previo fundado en ley anterior al hecho del proceso, ni juzgado } \\
\text { por comisiones especiales, o sacado de los jueces designados por la ley } \\
\text { antes del hecho de la causa. } \\
\text { Artículo 99. El Presidente de la Nación tiene las siguientes } \\
\text { atribuciones: } \\
\begin{array}{l}\text { 4. Nombra los magistrados de la Corte Suprema con acuerdo del } \\
\text { Senado por dos tercios de sus miembros presentes, en sesión pública, } \\
\text { convocada al efecto. }\end{array}\end{array}$ & $\begin{array}{l}\text { Hay estado de } \\
\text { derecho }\end{array}$ \\
\hline Participación & $\begin{array}{l}\text { Artículo 37. Esta Constitución garantiza el pleno ejercicio de los } \\
\text { derechos políticos. El sufragio es universal, igual, secreto y } \\
\text { obligatorio. } \\
\text { La igualdad real de oportunidades entre varones y mujeres para el } \\
\text { acceso a cargos electivos y partidarios se garantizará por acciones } \\
\text { positivas en la regulación de los partidos políticos y en el régimen } \\
\text { electoral. } \\
\text { Artículo 39. Los ciudadanos tienen el derecho de iniciativa para } \\
\text { presentar proyectos de ley en la Cámara de Diputados... } \\
\text { Artículo 40. El Congreso, a iniciativa de la Cámara de Diputados, } \\
\text { podrá someter a consulta popular un proyecto de ley. }\end{array}$ & $\begin{array}{l}\text { Existe la posibilidad } \\
\text { de participación }\end{array}$ \\
\hline $\begin{array}{l}\text { Competencia } \\
\text { partidaria }\end{array}$ & $\begin{array}{l}\text { Artículo 38. Los partidos políticos son instituciones fundamentales } \\
\text { del sistema democrático. Su creación y el ejercicio de sus actividades } \\
\text { son libres dentro del respeto a esta Constitución. } \\
\text { El Estado contribuye al sostenimiento económico de sus actividades y } \\
\text { de la capacitación de sus dirigentes. }\end{array}$ & $\begin{array}{l}\text { Existe competencia } \\
\text { partidaria }\end{array}$ \\
\hline $\begin{array}{l}\text { Rendición de } \\
\text { cuentas electoral } \\
\text { (vertical) }\end{array}$ & $\begin{array}{l}\text { Artículo 44. Un Congreso compuesto de dos Cámaras, una de } \\
\text { Diputados de la Nación y otra de Senadores de las provincias y de la } \\
\text { ciudad de Buenos Aires, será investido del Poder Legislativo de la } \\
\text { Nación. } \\
\text { Artículo 50. Los diputados durarán en su representación por cuatro } \\
\text { años, y son reelegibles. } \\
\text { Artículo 54. El Senado se compondrá de tres senadores por cada } \\
\text { provincia y tres por la ciudad de Buenos Aires, elegidos en forma } \\
\text { directa y conjunta. } \\
\text { Artículo 56. Los senadores duran seis años en el ejercicio de su } \\
\text { mandato, y son reelegibles indefinidamente. } \\
\text { Artículo 87. El Poder Ejecutivo de la Nación será desempeñado por } \\
\text { un ciudadano con el título de "Presidente de la Nación Argentina". } \\
\text { Artículo } 90 \text {. El Presidente y vicepresidente duran en sus funciones el }\end{array}$ & $\begin{array}{l}\text { Hay elecciones } \\
\text { recurrentes }\end{array}$ \\
\hline
\end{tabular}




\begin{tabular}{|c|c|c|}
\hline & $\begin{array}{l}\text { término de cuatro ańos y podrán ser reelegidos o sucederse } \\
\text { recíprocamente por un solo período consecutivo. } \\
\text { Artículo } 94 \text {. El Presidente y el vicepresidente de la Nación serán } \\
\text { elegidos directamente por el Pueblo, en doble vuelta (si fuera } \\
\text { necesario), según lo establece esta Constitución. A este fin el } \\
\text { territorio nacional conformará un distrito único. }\end{array}$ & \\
\hline $\begin{array}{c}\text { Rendición de } \\
\text { cuentas } \\
\text { interinstitucional } \\
\text { (horizontal) }\end{array}$ & $\begin{array}{l}\text { Artículo } 1^{\circ} \text {. La Nación Argentina adopta para su gobierno la forma } \\
\text { representativa republicana federal, según la establece la presente } \\
\text { Constitución. } \\
\text { Artículo } 5^{\circ} \text {. Cada provincia dictará para sí una Constitución bajo el } \\
\text { sistema representativo republicano, de acuerdo con los principios, } \\
\text { declaraciones y garantías de la Constitución Nacional; } \\
\text { Artículo 85. El control externo del sector público nacional en sus } \\
\text { aspectos patrimoniales, económicos, financieros y operativos, será } \\
\text { una atribución propia del Poder Legislativo. } \\
\text { Artículo 86. El Defensor del Pueblo es un órgano independiente } \\
\text { instituido en el ámbito del Congreso de la Nación. Su misión es la } \\
\text { defensa y protección de los derechos humanos y demás derechos, } \\
\text { garantías e intereses. } \\
\text { Artículo 87. El Poder Ejecutivo de la Nación será desempeñado por } \\
\text { un ciudadano con el título de "Presidente de la Nación Argentina". } \\
\text { Artículo 108. El Poder Judicial de la Nación será ejercido por una } \\
\text { Corte Suprema de Justicia, y por los demás tribunales inferiores que } \\
\text { el Congreso estableciere en el territorio de la Nación. } \\
\text { Artículo 120. El Ministerio Público es un órgano independiente con } \\
\text { autonomía funcional y autarquía financiera que tiene por función } \\
\text { promover la actuación de la justicia en defensa de la legalidad de los } \\
\text { intereses generales de la sociedad. } \\
\text { Artículo 121. Las provincias conservan todo el poder no delegado } \\
\text { por esta Constitución al Gobierno federal, y el que expresamente se } \\
\text { hayan reservado por pactos especiales al tiempo de su incorporación. } \\
\text { Ley n. 25.233. } \\
\text { Artículo 13. Créase la Oficina Anticorrupción en el ámbito del } \\
\text { Ministerio de Justicia y Derechos Humanos, que tendrá a su cargo la } \\
\text { elaboración y coordinación de programas de lucha contra la } \\
\text { corrupción y, en forma concurrente con la Fiscalía de Investigaciones } \\
\text { Administrativas, gozará de las competencias y atribuciones } \\
\text { establecidas en los artículos } 26 \text {, } 45 \text { y } 50 \text { de la Ley n. } 24.946 \text {. }\end{array}$ & $\begin{array}{l}\text { Hay pesos y } \\
\text { contrapesos }\end{array}$ \\
\hline Contenido & Constitución & Comentarios \\
\hline Libertad & $\begin{array}{l}\text { Artículo 14. Todos los habitantes de la Nación gozan de los } \\
\text { siguientes derechos: de trabajar y ejercer toda industria lícita; de } \\
\text { navegar y comerciar; de peticionar a las autoridades; de entrar, } \\
\text { permanecer, transitar y salir del territorio; de publicar sus ideas por la } \\
\text { prensa sin censura previa; de usar y disponer de su propiedad; de } \\
\text { asociarse con fines útiles; de profesar libremente su culto; de enseñar } \\
\text { y aprender. } \\
\text { Artículo 15. En la Nación Argentina no hay esclavos: los que hoy }\end{array}$ & $\begin{array}{l}\text { Hay libertad en la } \\
\text { ley }\end{array}$ \\
\hline
\end{tabular}




\begin{tabular}{|c|c|c|}
\hline & $\begin{array}{l}\text { existen quedan libres desde la jura de esta Constitución; } \\
\text { Artículo } 32 \text {. El Congreso federal no dictará leyes que restrinjan la } \\
\text { libertad de imprenta o establezcan sobre ella la jurisdicción federal. }\end{array}$ & \\
\hline Igualdad & $\begin{array}{l}\text { Artículo } \mathbf{8}^{\circ} \text {. Los ciudadanos de cada provincia gozan de todos los } \\
\text { derechos, privilegios e inmunidades inherentes al título de ciudadano } \\
\text { en las demás... } \\
\text { Artículo 16. La Nación Argentina no admite prerrogativas de sangre, } \\
\text { ni de nacimiento: no hay en ella fueros personales ni títulos de } \\
\text { nobleza. Todos sus habitantes son iguales ante la ley, y admisibles en } \\
\text { los empleos sin otra condición que la idoneidad. La igualdad es la } \\
\text { base del impuesto y de las cargas públicas. }\end{array}$ & $\begin{array}{l}\text { Hay igualdad en la } \\
\text { ley }\end{array}$ \\
\hline Resultado & Constitución & Comentarios \\
\hline $\begin{array}{c}\text { Respuesta } \\
\text { (Responsiveness) }\end{array}$ & $\begin{array}{l}\text { Artículo } 41 \text {. Todos los habitantes gozan del derecho a un ambiente } \\
\text { sano, equilibrado, apto para el desarrollo humano y para que las } \\
\text { actividades productivas satisfagan las necesidades presentes sin } \\
\text { comprometer las de las generaciones futuras; y tienen el deber de } \\
\text { preservarlo. }\end{array}$ & $\begin{array}{ll}\text { Hay } & \text { resultados } \\
\text { aparentes } & \end{array}$ \\
\hline
\end{tabular}

Fuente: Argentina (1994).

\section{Conclusión}

La Constitución de Argentina, como en Brasil, cuenta aparentemente con todos los entramados legales de una democracia. Hay Estado de Derecho, Participación, Competencia Partidaria, Responsabilidad Electoral, Libertad, Igualdad y, Resultados en la ley; los Ministros de Justicia son nombrados en contrapeso por los otros dos poderes. Existe la reelección en el poder ejecutivo; conteniendo éste, Presidente y Vicepresidente.

\section{México}

\section{Antecedentes}

El 31 de enero de 1917, terminada la Revolución y, tras dos meses de debates, el Constituyente cerró sesiones. El 5 de febrero se promulgó la nueva Constitución, con el nombre Constitución Política de los Estados Unidos Mexicanos que reformaba la del 5 de febrero de 1857, y entraría en vigor el 1 de mayo del mismo año. Contiene 136 artículos. 
Cuadro 3 - Comparativo México

\begin{tabular}{|c|c|c|}
\hline $\begin{array}{c}\text { Pais/ } \\
\text { Variable }\end{array}$ & México & Observaciones \\
\hline Procedimiento & Constitución & Comentarios \\
\hline $\begin{array}{l}\text { Estado de } \\
\text { derecho }\end{array}$ & $\begin{array}{l}\text { Artículo } 1^{\circ} \text {. En los Estados Unidos Mexicanos todas las personas } \\
\text { gozarán de los derechos humanos reconocidos en esta Constitución. } \\
\text { Queda prohibida toda discriminación. } \\
\text { Artículo 14. A ninguna ley se dará efecto retroactivo. } \\
\text { Artículo 96. Para nombrar a los Ministros de la Suprema Corte de } \\
\text { Justicia, el Presidente de la República someterá una terna a } \\
\text { consideración del Senado. }\end{array}$ & $\begin{array}{l}\text { Hay aparente estado } \\
\text { de derecho }\end{array}$ \\
\hline Participación & $\begin{array}{l}\text { Artículo 35. Son derechos del ciudadano: } \\
\text { I. Votar en las elecciones populares; } \\
\text { II. Poder ser votado para todos los cargos de elección popular; } \\
\text { III. Asociarse individual y libremente para tomar parte en forma } \\
\text { pacífica en los asuntos políticos del país; } \\
\text { VII. Iniciar leyes, } \\
\text { VIII. Votar en las consultas populares sobre temas de trascendencia } \\
\text { nacional. }\end{array}$ & $\begin{array}{l}\text { Hay posibilidad de } \\
\text { participación (no } \\
\text { directa). }\end{array}$ \\
\hline $\begin{array}{l}\text { Competencia } \\
\text { partidaria }\end{array}$ & $\begin{array}{l}\text { Artículo } 41 \text {. Los partidos políticos son entidades de interés público. } \\
\text { La ley garantizará que cuenten de manera equitativa con elementos } \\
\text { para llevar a cabo sus actividades. } \\
\text { III. Los partidos políticos nacionales y candidatos independientes } \\
\text { tendrán derecho al uso de manera permanente de los medios de } \\
\text { comunicación. } \\
\text { e) El tiempo establecido como de los partidos y de los candidatos } \\
\text { independientes, se distribuirá conforme a lo siguiente: el setenta por } \\
\text { ciento será entre los partidos políticos de acuerdo a los resultados de } \\
\text { la elección para diputados federales inmediata anterior y el treinta por } \\
\text { ciento restante dividido en partes iguales, de las cuales, hasta una de } \\
\text { ellas podrá ser asignada a los candidatos independientes en su } \\
\text { conjunto; } \\
\text { f) A cada partido sin representación en el Congreso de la Unión se le } \\
\text { asignará solamente la parte correspondiente al porcentaje igualitario. } \\
\text { En ningún momento podrán contratar, por sí o por terceras personas, } \\
\text { tiempos en cualquier modalidad de radio y televisión. } \\
\text { Artículo } 41 \text {. Apartado A. El Instituto Nacional Electoral es el } \\
\text { organismo público (en materia electoral). } \\
\text { Contará en su estructura con órganos de dirección, ejecutivos, } \\
\text { técnicos y de vigilancia. El Consejo General será su órgano superior } \\
\text { de dirección y se integrará por un consejero Presidente y diez } \\
\text { consejeros electorales, y concurrirán, con voz pero sin voto, los } \\
\text { consejeros del Poder Legislativo, los representantes de los partidos } \\
\text { políticos y un Secretario Ejecutivo; } \\
\text { El consejero Presidente y los consejeros electorales, serán electos por } \\
\text { el voto de las dos terceras partes de los miembros presentes de la }\end{array}$ & $\begin{array}{l}\text { Hay una } \\
\text { "diferenciada" } \\
\text { competencia } \\
\text { partidaria, aunque } \\
\text { existe posibilidad de } \\
\text { candidaturas } \\
\text { independientes. }\end{array}$ \\
\hline
\end{tabular}




\begin{tabular}{|c|c|c|}
\hline & Cámara de Diputados. & \\
\hline $\begin{array}{l}\text { Rendición de } \\
\text { cuentas electoral } \\
\text { (vertical) }\end{array}$ & $\begin{array}{l}\text { Artículo } 71 \text {. El derecho de iniciar leyes o decretos compete: } \\
\text { IV. A los ciudadanos en un número equivalente, por lo menos, al } \\
\text { cero punto trece por ciento de la lista nominal de electores. } \\
\text { Artículo } 41 \text {. La renovación de los poderes Legislativo y Ejecutivo se } \\
\text { realizará mediante elecciones libres, auténticas y periódicas. } \\
\text { Artículo 51. La Cámara de Diputados se compondrá de } \\
\text { representantes de la Nación, electos en su totalidad cada tres años. } \\
\text { Artículo 56. La Cámara de Senadores se integrará por ciento } \\
\text { veintiocho senadores, de los cuales, en cada Estado, dos serán } \\
\text { elegidos según el principio de votación mayoritaria relativa y uno será } \\
\text { asignado a la primera minoría. Los treinta y dos restantes serán } \\
\text { elegidos según el principio de representación proporcional, mediante } \\
\text { el sistema de listas votadas en una sola circunscripción plurinominal } \\
\text { nacional. Se renovará en su totalidad cada } 6 \text { años. } \\
\text { Artículo } 81 \text {. La elección del Presidente será directa. } \\
\text { Artículo 59. Los Senadores podrán ser electos hasta por dos periodos } \\
\text { consecutivos y los Diputados al Congreso de la Unión hasta por } \\
\text { cuatro. }\end{array}$ & $\begin{array}{l}\text { Hay elecciones } \\
\text { recurrentes }\end{array}$ \\
\hline $\begin{array}{l}\text { Rendición de } \\
\text { cuentas } \\
\text { interinstitucional } \\
\text { (horizontal) }\end{array}$ & $\begin{array}{l}\text { Artículo 49. El Supremo Poder de la Federación se divide para su } \\
\text { ejercicio en Legislativo, Ejecutivo y Judicial. } \\
\text { Artículo 90. La Administración Pública Federal será centralizada y } \\
\text { paraestatal. } \\
\text { Artículo 115. Los estados adoptarán, la forma de gobierno } \\
\text { republicano, teniendo como base, el municipio libre. } \\
\text { II. El Municipio será gobernado por un Ayuntamiento, integrado por } \\
\text { un Presidente Municipal y un número de regidores y síndicos. } \\
\text { Artículo 99. El Tribunal Electoral será, la máxima autoridad } \\
\text { jurisdiccional en la materia. } \\
\text { Al Tribunal Electoral le corresponde resolver en forma definitiva e } \\
\text { inatacable, en los términos de esta Constitución y según lo disponga } \\
\text { la ley, sobre: } \\
\text { I. Las impugnaciones en la elección de diputados y senadores; } \\
\text { II. Las impugnaciones que en la elección de Presidente. } \\
\text { Artículo 102. A. El Ministerio Público de la Federación se } \\
\text { organizará en una Fiscalía General de la República. } \\
\text { III. El Senado, designará al Fiscal General dentro del plazo de diez } \\
\text { días. Si no hace la designación, el Ejecutivo lo designará. } \\
\text { IV. El Fiscal podrá ser removido por el Ejecutivo Federal. } \\
\text { B. El Congreso y las legislaturas de las entidades federativas, } \\
\text { establecerán organismos de protección de los derechos humanos. } \\
\text { Formularán recomendaciones, no vinculatorias. } \\
\text { Artículo 108. Para efecto de responsabilidades de los servidores: } \\
\text { El Presidente de la República, durante el tiempo de su encargo, sólo } \\
\text { podrá ser acusado por traición a la patria y delitos graves. } \\
\text { Las faltas administrativas graves serán investigadas por la Auditoría } \\
\text { Superior de la Federación (de) la Cámara de Diputados y los órganos }\end{array}$ & $\begin{array}{l}\text { No hay pesos y } \\
\text { contrapesos claros }\end{array}$ \\
\hline
\end{tabular}




\begin{tabular}{|c|c|c|}
\hline & $\begin{array}{l}\text { de control (del) Ejecutivo, o por sus homólogos en las entidades } \\
\text { federativas, y serán resueltas por el Tribunal de Justicia } \\
\text { Administrativa (Nombrados por el Presidente con la ratificación del } \\
\text { Senado, Art. 43, Ley Orgánica del Tribunal Federal de Justicia } \\
\text { Administrativa (LOTFJA). } \\
\text { Artículo 110. (Todos) Podrán ser sujetos de juicio político. } \\
\text { Las resoluciones de las Cámaras son inatacables. } \\
\text { Artículo 113. El Sistema Nacional Anticorrupción es la instancia de } \\
\text { coordinación entre las autoridades de todos los órdenes de gobierno } \\
\text { en la materia. } \\
\text { I. Contará con un Comité Coordinador que estará integrado por los } \\
\text { titulares de la Auditoría Superior de la Federación; de la Fiscalía } \\
\text { Especializada en Combate a la Corrupción; de la secretaría del } \\
\text { Ejecutivo Federal responsable del control interno; por el presidente } \\
\text { del Tribunal Federal de Justicia Administrativa; el presidente del } \\
\text { organismo garante que establece el artículo 6o. de esta Constitución; } \\
\text { así como por un representante del Consejo de la Judicatura Federal y } \\
\text { otro del Comité de Participación Ciudadana; } \\
\text { II. El Comité de Participación Ciudadana del Sistema deberá } \\
\text { integrarse por cinco ciudadanos (electos por el Senado, Ley } \\
\text { Secundaria Art. 18). } \\
\text { III. Corresponderá al Comité Coordinador del Sistema (Principal), } \\
\text { en los términos que determine la Ley: } \\
\text { e) La elaboración de un informe que contenga los avances y } \\
\text { resultados del ejercicio de sus funciones y de la aplicación de políticas } \\
\text { y programas. No vinculantes. }\end{array}$ & \\
\hline Contenido & Constitución & Comentarios \\
\hline Libertad & $\begin{array}{l}\text { Artículo 6o. La manifestación de las ideas no será objeto de ninguna } \\
\text { inquisición judicial o administrativa. } \\
\text { A. Para el ejercicio del derecho a la información, la Federación y las } \\
\text { entidades federativas, se regirán por los siguientes principios y bases: } \\
\text { I. Toda la información, es pública y sólo podrá ser reservada } \\
\text { temporalmente por razones de interés público...la ley determinará los } \\
\text { supuestos específicos bajo los cuales procederá la declaración de } \\
\text { inexistencia de la información. } \\
\text { VIII. La Federación contará con un organismo autónomo } \\
\text { especializado. Sus resoluciones son vinculatorias, definitivas e } \\
\text { inatacables. } \\
\text { Se integrará por siete comisionados. La Cámara de Senadores } \\
\text { nombrará a los comisionados. El nombramiento podrá ser objetado } \\
\text { por el Presidente de la República. } \\
\text { B. En materia de radiodifusión y telecomunicaciones: } \\
\text { V. La ley establecerá un organismo público descentralizado con } \\
\text { autonomía técnica, operativa, de decisión y de gestión. } \\
\text { El organismo público contará con un Consejo Ciudadano. } \\
\text { Su Presidente será designado, a propuesta del Ejecutivo. }\end{array}$ & $\begin{array}{l}\text { Hay una aparente } \\
\text { libertad }\end{array}$ \\
\hline
\end{tabular}




\begin{tabular}{|c|c|c|}
\hline Igualdad & $\begin{array}{l}\text { Artículo } 2^{\circ} \text {. A. Esta Constitución reconoce y garantiza el derecho de } \\
\text { los pueblos indígenas a la libre determinación y, su autonomía. } \\
\text { Artículo 5o. A ninguna persona podrá impedirse que se dedique a la } \\
\text { profesión, industria, o trabajo que le acomode, siendo lícitos. } \\
\text { Artículo } 1^{\circ} \text {. Las normas relativas a los derechos humanos se } \\
\text { interpretarán de conformidad con esta Constitución y con los } \\
\text { tratados internacionales de la materia favoreciendo en todo tiempo a } \\
\text { las personas la protección más amplia. }\end{array}$ & $\begin{array}{l}\text { Hay una posibilidad } \\
\text { igualitaria ante la ley }\end{array}$ \\
\hline Resultado & Constitución & Comentarios \\
\hline $\begin{array}{c}\text { Respuesta } \\
\text { (Responsiveness) }\end{array}$ & $\begin{array}{l}\text { Artículo 3o. Toda persona tiene derecho a recibir educación. } \\
\text { Artículo 4o. (...) Toda persona tiene derecho a la alimentación } \\
\text { nutritiva, suficiente y de calidad. El Estado lo garantizará. } \\
\text { Toda persona tiene derecho a la protección de la salud. } \\
\text { Toda persona tiene derecho a un medio ambiente sano para su } \\
\text { desarrollo y bienestar. El Estado garantizará. } \\
\text { Toda persona tiene derecho al acceso, disposición y saneamiento de } \\
\text { agua para consumo personal y doméstico en forma suficiente, } \\
\text { salubre, aceptable y asequible. El Estado garantizará. } \\
\text { Toda familia tiene derecho a disfrutar de vivienda digna. } \\
\text { Artículo 123. Toda persona tiene derecho al trabajo digno; } \\
\text { XXIX. Será de utilidad pública la Ley del Seguro Social, y ella } \\
\text { comprenderá seguros de invalidez, de vejez, de vida, de cesación } \\
\text { involuntaria del trabajo, de enfermedades y accidentes, entre otras. }\end{array}$ & $\begin{array}{l}\text { Existen resultados en } \\
\text { la ley }\end{array}$ \\
\hline
\end{tabular}

Fuente: México (1917).

\section{Conclusión}

$\mathrm{Al}$ igual que Brasil y Argentina, la Constitución mexicana contiene todos los elementos considerados por Morlino (2008) y Alcántara (2008), aunque difiere algunas cosas, particularmente los pesos y contrapesos son más débiles, toda vez que el sistema da primacía al Presidente aunque ciertamente no puede ser reelecto; este por su vez, no tiene un Vicepresidente que tampoco lo contraponga. Por otro lado, el Poder Judicial, sigue siendo de contrapeso, nominado por los otros dos poderes.

\section{Paraguay}

\section{Antecedentes}

La Constitución Paraguaya data de 1992 y marca la redemocratización del país que pasara por una de las más largas y crueles dictaduras de América Latina bajo el mando de Alfredo Stroessner en el período 1954 a 1989. A pesar del modelo de transición y de las características que marcaron el fin de la dictadura paraguaya, la constitución de 1992 que rige actualmente es un marco en el largo y difícil proceso 
76 | Manuel Edeza, Jorge Giménez, Patricia Rocha, Thiago Engelman e Leonardo de Alancaster

de fortalecimiento democrático de Paraguay. Contiene 291 artículos, siendo de las más largas de América Latina.

Cuadro 4 - Comparativo Paraguay

\begin{tabular}{|c|c|c|}
\hline $\begin{array}{c}\text { Pais/ } \\
\text { Variable }\end{array}$ & Paraguay & Observaciones \\
\hline Procedimiento & Constitución & Comentarios \\
\hline $\begin{array}{l}\text { Estado de } \\
\text { derecho }\end{array}$ & $\begin{array}{l}\text { Artículo } \mathbf{1}^{\circ} \text {. La República del Paraguay se constituye en Estado } \\
\text { Social de Derecho. } \\
\text { Artículo } 46 \text {. Todos los habitantes de la República son iguales en } \\
\text { dignidad y derechos... } \\
\text { Artículo 47. El Estado garantizará a todos los habitantes de la } \\
\text { República: } \\
\text { 2) La igualdad ante las leyes } \\
\text { Artículo 250. Los ministros de la Corte Suprema de Justicia } \\
\text { prestarán juramento o promesa ante el Congreso, al asumir sus } \\
\text { cargos. }\end{array}$ & $\begin{array}{l}\text { Hay estado de } \\
\text { derecho. } \\
\text { No es clara en } \\
\text { cuanto a la forma de } \\
\text { elección del Poder } \\
\text { Judicial, aunque se } \\
\text { asume que es electo } \\
\text { por el Congreso en } \\
\text { conjunción con el } \\
\text { Ejecutivo, aunque } \\
\text { no está expresa en la } \\
\text { Ley Constitucional. }\end{array}$ \\
\hline Participación & $\begin{array}{l}\text { Artículo } 117 \text {. Los ciudadanos, sin distinción de sexo, tienen derecho } \\
\text { a participar en los asuntos públicos directamente o por medio de sus } \\
\text { representantes. } \\
\text { Artículo } 121 \text {. El referéndum legislativo, decidido por ley, podrá o no } \\
\text { ser vinculante. } \\
\text { Artículo } 123 \text {. Se reconoce a los electores el derecho a la iniciativa } \\
\text { popular para proponer al Congreso proyectos de ley. } \\
\text { Artículo } 125 \text {. Todos los ciudadanos tienen el derecho de asociarse } \\
\text { libremente en partidos o en movimientos políticos para concurrir, } \\
\text { por métodos democráticos. }\end{array}$ & $\begin{array}{l}\text { Existe la posibilidad } \\
\text { de participación }\end{array}$ \\
\hline $\begin{array}{l}\text { Competencia } \\
\text { partidaria }\end{array}$ & $\begin{array}{l}\text { Artículo 126. Los partidos y movimientos políticos, en su } \\
\text { funcionamiento, no podrán: } \\
\text { 1) Recibir auxilio económico del extranjero } \\
\text { 2) Apelar a la violencia } \\
\text { 3) Tener como fin substituir el régimen del país. } \\
\text { Todos pueden participar libremente a cualquier partido. No hay } \\
\text { legislación respecto a umbrales o porcentajes mínimos condicionados } \\
\text { a la permanencia. En cuanto al financiamiento, la constitución } \\
\text { nacional no trata este tema. } \\
\text { Algo importante es que en Paraguay sí es permitido candidaturas sin } \\
\text { partido, basta que formes un movimiento político criado para una } \\
\text { elección específica. El capítulo IV del código trata sobre eso. } \\
\text { Lo que sí hay es el Código Electoral Paraguayo promulgado por ley } \\
\text { 834/96 } \\
\text { El capítulo II trata sobre la financiación, al referirse que el } \\
\text { Presupuesto General de Gastos de la nación contemplará recursos } \\
\text { para los partidos. }\end{array}$ & $\begin{array}{l}\text { Existe competencia } \\
\text { partidaria }\end{array}$ \\
\hline
\end{tabular}




\begin{tabular}{|c|c|c|}
\hline $\begin{array}{l}\text { Resndición de } \\
\text { cuentas electoral } \\
\text { (vertical) }\end{array}$ & $\begin{array}{l}\text { Artículo 120. Son electores los ciudadanos paraguayos radicados en } \\
\text { el territorio nacional, sin distinción, que hayan cumplido dieciocho } \\
\text { años. Los ciudadanos son electores y elegibles. Los extranjeros con } \\
\text { radicación definitiva tendrán los mismos derechos en las elecciones } \\
\text { municipales. } \\
\text { Artículo 156. El territorio nacional se divide en departamentos y } \\
\text { municipios... } \\
\text { Artículo } 161 \text {. El gobierno de cada departamento durará cinco ańos } \\
\text { en sus funciones. No podrá ser reelecto. } \\
\text { Artículo } 187 \text {. Los senadores y diputados serán elegidos en comicios } \\
\text { simultáneos con los presidenciales. Los legisladores durarán cinco } \\
\text { ańos y podrán ser reelectos. } \\
\text { Artículo } 229 \text {. El presidente de la República y el Vicepresidente } \\
\text { durarán cinco ańos improrrogables. No podrán ser reelectos. }\end{array}$ & $\begin{array}{l}\text { Hay elecciones } \\
\text { recurrentes }\end{array}$ \\
\hline $\begin{array}{l}\text { Rendición de } \\
\text { cuentas } \\
\text { interinstitucional } \\
\text { (horizontal) }\end{array}$ & $\begin{array}{l}\text { Artículo 28. Se reconoce el derecho de las personas a recibir } \\
\text { información veraz, responsable y ecuánime. } \\
\text { Toda persona afectada por la difusión de una información falsa, } \\
\text { distorsionada o ambigua tiene derecho a exigir su rectificación o su } \\
\text { aclaración por el mismo medio y en las mismas condiciones que haya } \\
\text { sido divulgada, sin perjuicio de los demás derechos compensatorios. } \\
\text { Reglamentado en la Ley n. 5.282/2014 "De libre Acceso Ciudadano } \\
\text { a la Información Pública y Transparencia Gubernamental" } \\
\text { Artículo 6. Las fuentes públicas deberán habilitar una Oficina de } \\
\text { Acceso a la Información Pública, en la que se recibirán y responderán } \\
\text { las solicitudes. } \\
\text { Artículo 281. La Contraloría General de la República es el órgano } \\
\text { de control de las actividades económicas y financieras del Estado de } \\
\text { los departamentos y de las municipalidades... } \\
\text { La Contraloría General de la República será designada por la Cámara } \\
\text { de Diputados por mayoría absoluta, de ternas de candidatos } \\
\text { propuestos por la Cámara de Senadores. Durán cinco años en sus } \\
\text { funciones, los cuales no serán coincidentes con las del mandato } \\
\text { presidencial. Pueden ser confirmados en el cargo sólo por un periodo } \\
\text { más. } \\
\text { Artículo 282. El Presidente de la República enviará a la Contraloría } \\
\text { la liquidación presupuestaria del ańo anterior. La Contraloría deberá } \\
\text { elevar el informe y dictamen al Congreso. }\end{array}$ & $\begin{array}{l}\text { Hay ciertos pesos y } \\
\text { contrapesos }\end{array}$ \\
\hline Contenido & Constitución & Comentarios \\
\hline Libertad & $\begin{array}{l}\text { Artículo 24. Quedan reconocidas la libertad religiosa, la de culto y la } \\
\text { ideológica, sin más limitaciones que las establecidas en esta } \\
\text { Constitución. } \\
\text { Artículo } 32 \text {. Las personas tienen derecho a reunirse y manifestarse } \\
\text { pacíficamente, sin necesidad de permiso así como el derecho a no ser } \\
\text { obligada a participar de tales actos. } \\
\text { Artículo } 25 \text {. Se garantiza el pluralismo ideológico. } \\
\text { Artículo } 42 \text {. Toda persona es libre de asociarse o de agremiarse. }\end{array}$ & Hay libertad \\
\hline
\end{tabular}




\begin{tabular}{|c|l|l|}
\hline \multirow{3}{*}{ Igualdad } & $\begin{array}{l}\text { EL capítulo VI que incluye los artículos 68 a 72 trata del derecho a la } \\
\text { salud, especialmente la idea de que el Estado deberá promover dicho } \\
\text { derecho. }\end{array}$ & $\begin{array}{l}\text { Hay igualdad en la } \\
\text { ley artículo VII trata del derecho a la educación y de modo especial el } \\
\text { artículo 76 trata sobre la obligación del Estado con el Derecho a la } \\
\text { Educación. Ya el capítulo 9. VIII. Trata sobre los derechos laborales } \\
\text { y sobre la libertad sindical y el Capítulo IX trata sobre los derechos } \\
\text { económicos y de la Reforma Agraria }\end{array}$ \\
\hline Resultado & \multicolumn{1}{|c}{ Constitución } & \multicolumn{1}{c|}{ Comentarios } \\
\hline $\begin{array}{c}\text { Respuesta } \\
\text { (Responsiveness) }\end{array}$ & No especificado. & $\begin{array}{l}\text { Hay resultados en la } \\
\text { ley }\end{array}$ \\
\hline
\end{tabular}

Fuente: Paraguay (1992).

\section{Conclusión}

El marco constitucional de Paraguay puede ser considerado en relativas condiciones de viabilizar el ideal democrático. Por un lado la Constitución Nacional garantiza la igualdad de condiciones ante las leyes, contempla una relativa participación en las instancias de poder como las elecciones, referéndum o leyes de iniciativa popular, garantiza igualmente la pluralidad de ideas y el derecho a la libre asociación entre otros derechos fundamentales en el marco democrático. Pero al mismo tiempo, establece algunas prohibiciones que a nuestro criterio limitan la posibilidad de que se pueda considerar el marco constitucional como suficientemente capaz de promover la Democracia.

\section{Uruguay}

\section{Antecedentes}

La primera Constitución de Uruguay fue aprobada por la Asamblea General Constituyente y Legislativa del Estado el 10 de septiembre de 1829 y jurada por el pueblo el 18 de julio de 1830. Ha sufrido varias reformas; el texto vigente es básicamente el de 1967, el cual, tuvo varias enmiendas posteriores, en particular, la reforma constitucional de 1997. Contiene 332 artículos, siendo de las más extensas en el Continente. 
Cuadro 5 - Comparativo Uruguay

\begin{tabular}{|c|c|c|}
\hline $\begin{array}{c}\text { Pais/ } \\
\text { Variable }\end{array}$ & Uruguay & Observaciones \\
\hline Procedimiento & Constitución & Comentarios \\
\hline $\begin{array}{l}\text { Estado de } \\
\text { derecho }\end{array}$ & $\begin{array}{l}\text { Artículo } 7^{\circ} \text {. Los habitantes de la República tienen derecho a ser } \\
\text { protegidos en el goce de su vida, honor, libertad, seguridad, trabajo y } \\
\text { propiedad. . } \\
\text { Artículo } 8^{\circ} \text {. Todas las personas son iguales ante la ley no } \\
\text { reconociéndose otra distinción entre ellas sino la de los talentos o las } \\
\text { virtudes. } \\
\text { Artículo 12. Nadie puede ser penado ni confinado sin forma de } \\
\text { proceso y sentencia legal. } \\
\text { Artículo 236. Los miembros de la Suprema Corte de Justicia serán } \\
\text { designados por la Asamblea General por dos tercios de votos del total } \\
\text { de sus componentes. }\end{array}$ & $\begin{array}{l}\text { Hay estado de } \\
\text { derecho. } \\
\text { Aparentemente } \\
\text { habría un poder } \\
\text { judiciario más } \\
\text { equilibrado en } \\
\text { cuanto a su elección. }\end{array}$ \\
\hline Participación & $\begin{array}{l}\text { Artículo 77. Todo ciudadano es miembro de la soberanía de la } \\
\text { Nación; como tal es elector y elegible en los casos y formas que se } \\
\text { designarán. } \\
\text { Artículo } 78 \text {. Tienen derecho al sufragio, sin necesidad de obtener } \\
\text { previamente ciudadanía legal, teniendo residencia habitual de quince } \\
\text { ańos. } \\
\text { Artículo 30. Todo habitante tiene derecho de petición para ante } \\
\text { todas y cualesquiera autoridades de la República. }\end{array}$ & Hay participación \\
\hline $\begin{array}{c}\text { Competencia } \\
\text { partidaria }\end{array}$ & $\begin{array}{l}\text { Artículo 77, numerales: } \\
\text { 11) El Estado velará por asegurar a los Partidos políticos la más } \\
\text { amplia libertad. } \\
\text { Ley n. } 18.485 \\
\text { Artículo } 1^{\circ} \text { - Declárase de interés nacional para el afianzamiento del } \\
\text { sistema democrático republicano la existencia de partidos políticos y } \\
\text { su libre funcionamiento. } \\
\text { Artículo } 2^{\circ} \text { - A tales efectos el Estado contribuirá a solventar los } \\
\text { gastos de los partidos políticos en su funcionamiento; } \\
\text { Artículo } 3^{\circ} \text {.- A los efectos de esta ley, los partidos políticos son } \\
\text { asociaciones de personas sin fines de lucro, que se organizan a los } \\
\text { efectos del ejercicio colectivo de la actividad política en todas sus } \\
\text { manifestaciones. }\end{array}$ & $\begin{array}{l}\text { Hay semi- } \\
\text { competencia } \\
\text { partidaria }\end{array}$ \\
\hline $\begin{array}{l}\text { Rendición de } \\
\text { cuentas electoral } \\
\quad \text { (vertical) }\end{array}$ & $\begin{array}{l}\text { Artículo 82. La Nación adopta para su Gobierno la forma } \\
\text { democrática republicana. } \\
\text { Artículo 152. El Presidente y Vicepresidente durarán cinco ańos en } \\
\text { sus funciones, y para volver a desempeñarlas se requerirá que hayan } \\
\text { transcurrido cinco ańos. } \\
\text { Artículo 88. La Cámara de Representantes se compondrá de noventa } \\
\text { y nueve miembros, con arreglo a un sistema de representación } \\
\text { proporcional en el que se tomen en cuenta los votos emitidos a favor } \\
\text { de cada lema en todo el país. } \\
\text { Artículo 89. Los Representantes durarán cinco años en sus }\end{array}$ & $\begin{array}{lr}\text { Hay elecciones } \\
\text { recurrentes } \\
\text { competitivas }\end{array}$ \\
\hline
\end{tabular}




\begin{tabular}{|c|c|c|}
\hline & $\begin{array}{l}\text { funciones. } \\
\text { Artículo 94. La Cámara de Senadores se compondrá de treinta } \\
\text { miembros, elegidos directamente por el pueblo, en una sola } \\
\text { circunscripción electoral. } \\
\text { Artículo 95. Los Senadores serán elegidos por el sistema de } \\
\text { representación proporcional integral. } \\
\text { Artículo 97. Los Senadores durarán cinco años en sus funciones. } \\
\text { Artículo 322. Habrá una Corte Electoral que tendrá las siguientes } \\
\text { facultades: } \\
\text { A) Conocer en todo lo relacionado con los actos y procedimientos } \\
\text { electorales. } \\
\text { B) Ejercer la superintendencia directiva, correccional, consultiva y } \\
\text { económica sobre los órganos electorales. } \\
\text { C) Decidir en última instancia sobre todas las apelaciones y reclamos } \\
\text { que se produzcan, y ser juez de las elecciones de todos los cargos } \\
\text { electivos, de los actos de plebiscito y referéndum. }\end{array}$ & \\
\hline $\begin{array}{c}\text { Rendición de } \\
\text { cuentas } \\
\text { interinstitucional } \\
\text { (horizontal) }\end{array}$ & $\begin{array}{l}\text { Artículo 149. El Poder Ejecutivo será ejercido por el Presidente de la } \\
\text { República. } \\
\text { Artículo 150. Habrá un Vicepresidente, que en todos los casos de } \\
\text { vacancia temporal o definitiva de la Presidencia deberá desempeńarla } \\
\text { con sus mismas facultades y atribuciones. } \\
\text { Artículo 83. El Poder Legislativo será ejercido por la Asamblea } \\
\text { General. } \\
\text { Artículo 84. Esta se compondrá de dos Cámaras; una de } \\
\text { Representantes y otra de Senadores, las que actuarán separada o } \\
\text { conjuntamente, según las distintas disposiciones de la presente } \\
\text { Constitución. } \\
\text { Artículo 93. Compete a la Cámara de Representantes el derecho } \\
\text { exclusivo de acusar ante la Cámara de Senadores a los miembros a } \\
\text { todos los miembros de los órganos del Estado. } \\
\text { Artículo 102. A la Cámara de Senadores corresponde abrir juicio } \\
\text { público a los acusados por la Cámara de Representantes. } \\
\text { Artículo 85. A la Asamblea General compete: } 5^{\circ} \text { ) Aprobar o } \\
\text { reprobar, en todo o en parte, las cuentas que presente el Poder } \\
\text { Ejecutivo. } \\
\text { Artículo 119. Cada una de las Cámaras tiene facultad, por } \\
\text { resolución de un tercio de votos del total de sus componentes, de } \\
\text { hacer venir a Sala a los Ministros de Estado para pedirles y recibir los } \\
\text { informes que estime convenientes. } \\
\text { Artículo 120. Las Cámaras podrán nombrar comisiones } \\
\text { parlamentarias de investigación o para suministrar datos con fines } \\
\text { legislativos. } \\
\text { Artículo 121. Cualquiera de las Cámaras podrá formular } \\
\text { declaraciones. } \\
\text { Artículo 147. Cualquiera de las Cámaras podrá juzgar la gestión de } \\
\text { los Ministros de Estado, proponiendo que la Asamblea General, en } \\
\text { sesión de ambas Cámaras, declare que se censuran sus actos de } \\
\text { administración o de gobierno. }\end{array}$ & $\begin{array}{l}\text { Hay pesos y } \\
\text { contrapesos }\end{array}$ \\
\hline
\end{tabular}




\begin{tabular}{|c|c|c|}
\hline & $\begin{array}{l}\text { Artículo 211. Compete al Tribunal de Cuentas: } \\
\text { A) Dictaminar e informar en materia de presupuestos. } \\
\text { B) Intervenir preventivamente en los gastos y los pagos. } \\
\text { C) Dictaminar e informar respecto de la rendición de cuentas y } \\
\text { gestiones de todos los órganos del Estado. } \\
\text { Ley de Acceso a la Información Pública n. } 18.381 \\
\text { Artículo 19. Crea la Unidad de Acceso a la Información Pública } \\
\text { Ley n. 17.060. Normas referidas al uso indebido del poder } \\
\text { público. } \\
\text { Artículo 4. Crea la Junta de Transparencia y Ética Pública }\end{array}$ & \\
\hline Contenido & Constitución & Comentarios \\
\hline Libertad & $\begin{array}{l}\text { Artículo 29. Es enteramente libre en toda materia la comunicación } \\
\text { de pensamientos por palabras, escritos privados o publicados en la } \\
\text { prensa, o por cualquier otra forma de divulgación, sin necesidad de } \\
\text { previa censura. } \\
\text { Artículo 36. Toda persona puede dedicarse al trabajo, cultivo, } \\
\text { industria, comercio, profesión o cualquier otra actividad lícita. } \\
\text { Artículo 38. Queda garantido el derecho de reunión pacífica y sin } \\
\text { armas. } \\
\text { Artículo 39. Todas las personas tienen el derecho de asociarse. }\end{array}$ & Hay libertad \\
\hline Igualdad & $\begin{array}{l}\text { Artículo 8. Todas las personas son iguales ante la ley. } \\
\text { Artículo 68. Queda garantida la libertad de enseñanza. } \\
\text { Artículo } 41 \text {. El cuidado y educación de los hijos para que éstos } \\
\text { alcancen su plena capacidad corporal, intelectual y social, es un deber } \\
\text { y un derecho de los padres. Quienes tengan a su cargo numerosa } \\
\text { prole tienen derecho a auxilios compensatorios, siempre que los } \\
\text { necesiten. }\end{array}$ & Hay igualdad \\
\hline Resultado & Constitución & Comentarios \\
\hline $\begin{array}{c}\text { Respuesta } \\
\text { (Responsiveness) }\end{array}$ & No especificado. & $\begin{array}{l}\text { Hay resultados en la } \\
\text { ley }\end{array}$ \\
\hline
\end{tabular}

Fuente: Uruguay (1967).

\section{Conclusión}

Después de hacer un análisis de los artículos de la constitución uruguaya, se puede afirmar que legalmente hablando concede a los uruguayos muchos derechos legales de democracia, porque de algún modo todos los indicativos considerados son contemplados por ella; es llamativo lo extenso de su redacción; en los puntos a resaltar a favor, hay que decir que el poder Judiciario a diferencia de los demás países, es nominado directamente por el Congreso o Asamblea Nacional, aunque ciertamente, constituida también por el Vicepresidente. Por otro lado, la reelección es posible de ambos cargos en el ejecutivo, Presidente y Vicepresidente, pero con un periodo intercalado. 
82 | Manuel Edeza, Jorge Giménez, Patricia Rocha, Thiago Engelman e Leonardo de Alancaster

\section{Responsiveness}

Ciertamente, muchas de las constituciones marcan algunas de sus pretensiones o responsivenesss con sus ciudadanos; algunos de ellos, plasmados en el texto constitucional, como el caso mexicano y el argentino; la intención de generar salud, educación de calidad, vivienda digna, trabajo para todos; no obstante, lo cierto es que la realidad los alcanza y, salvo el caso de Uruguay y, precisamente de algún modo la Argentina, que ha logrado generar algo de satisfactores para su población, la mayoría de las democracias analizadas distan mucho de ser las grandes proveedoras de la calidad de vida de sus habitantes, quizá tuvieran razón Levine y Molina (2007), y eso no debiera ser asunto de la democracia; no obstante y, considerado como una de las dimensiones de Morlino (2008) y Alcántara (2008), sería una asignatura pendiente.

Abajo (Tablas 3 y 4), se recogen 3 indicadores sustantivos para medir económicamente la calidad de vida de los ciudadanos: el PIB Per Cápita 2015 (en dólares), el Índice de Desarrollo o Desenvolvimiento Humano (IDH-2015) y el Índice de GINI (2014, no había datos de todos para 2015), que mide las desigualdades, al tiempo que son comparados con algunas democracias más desarrolladas, los resultados son contundentes.

Uruguay y Argentina, conservan un PIB per cápita más elevado, pero comparado con el menor de los más exitosos, no alcanzan ni la mitad de ese nivel. Por otro lado, el IDH, que comprendería un 1,000 el máximo nivel, alcanza en Argentina con 0,795 el nivel más alto, pero del mismo modo, comparado con los países desarrollados de la muestra, el más bajo de ellos es de 0,925; respecto al Índice de GINI, que mide la desigualdad, o la diferencia entre el quintal más pobre contra el más rico y, donde contrario al IDH, 0 significa igualdad y 1, total desigualdad, el mejor evaluado es Uruguay, con un ,397, no obstante en los países ricos, esa desigualdad llega apenas al ,352 el más alto.

Tabla 3 - Resultados PIBpc, IDH y GINI países de la muestra

\begin{tabular}{l|c|c|c|c|c}
\hline \multicolumn{1}{c|}{ Variables } & Brasil & Argentina & México & Paraguay & Uruguay \\
\hline PIBpc 2015 & 8802 & 13428 & 9592 & 4142 & 16092 \\
\hline IDH 2015 & 0,754 & 0,827 & 0,762 & 0,693 & 0,795 \\
\hline IGINI 2014 &, 406 &, 445 &, 483 &, 524 &, 397 \\
\hline
\end{tabular}

Fuente: PIB Per Cápita (2015), Índice de Desarrollo Humano (2015) y Índice de GINI (2014). 
Tabla 4 - Resultados PIBpc, IDH y GINI, algunos países de los más ricos

\begin{tabular}{l|c|c|c|c|c}
\hline \multicolumn{1}{c|}{ Variables } & Noruega & Australia & Suiza & Alemania & Dinamarca \\
\hline PIBpc 2015 & 76266 & 51642 & 82178 & 41267 & 51424 \\
\hline IDH 2015 & 0,949 & 0,939 & 0,939 & 0,926 & 0,925 \\
\hline IGINI 2014 &, 258 &, 352 &, 337 &, 283 &, 247 \\
\hline
\end{tabular}

Fuente: PIB Per Cápita (2015), Índice de Desarrollo Humano (2015) y Índice de GINI (2014).

\section{Conclusión general}

Es evidente que el análisis de las constituciones de los países analizados, guardan en su mayoría un aparente formato democrático, con Estado de Derecho, posibilidades de Participación, Competencia Partidaria (salvo el caso de México que es muy limitativo de alguna manera), Responsabilidad Electoral, Libertad e Igualdad; no obstante, la parte que más adolecen, consideramos, es la de la Responsabilidad Interinstitucional, particularmente en lo que tiene que ver a la Transparencia y Rendición de Cuentas y los Resultados.

Si bien es cierto, la mayoría de los países contienen órganos o legislaciones en materia de transparencia, el Tribunal de Cuentas en el Brasil o su Ley Anticorrupción; la Defensoría del Pueblo en Argentina y su Oficina Anticorrupción; en México, un Sistema Nacional Anticorrupción; en Paraguay la Ley n. 5.282 (2014), que Obliga a la Constitución de Oficinas Públicas en las instancias Gubernamentales para el acceso y provisión de información pública, además de la Contraloría Nacional o Federal; en Uruguay, el Tribunal de Cuentas y las Leyes n. 18.381 (2008) y n. 17.060 (1999) para la información y la ética pública, todas se entrampan, en muchos de los casos en cuestiones "legales" o burocráticas; en México, es claro como el Órgano Garante, como ellos mismos lo llaman, para la información pública, constitucionalmente es puesto y removido a discreción por el Presidente; por otro lado, como ya se comentó, los Resultados o responsiveness, que habría que ver, hasta donde estarán ligados. La falta de transparencia genera Impunidad y Corrupción y afecta sin lugar a dudas el buen funcionamiento de las democracias en cuestión.

El Reporte Latinobarómetro 1995-2015 (Tabla 5), que incluyó precisamente estas vertientes, puede comprobar como los niveles de Transparencia y Corrupción en casi todos los países de América Latina, continúan como una asignatura pendiente y afectan el funcionamiento de las democracias. Sólo el $36 \%$ de la población entrevistada en dicho reporte, consideró había algo o mucho de transparencia y, los países en cuestión arrojaron las siguientes cifras: Uruguay 61\%, Argentina 34\%, 
84 | Manuel Edeza, Jorge Giménez, Patricia Rocha, Thiago Engelman e Leonardo de Alancaster

Paraguay 31\%, México 26\% y, Brasil, tan sólo un 16\%, es decir, 4 de los 5, por abajo del promedio Latinoamericano.

En cuanto a la Corrupción, las cifras no son tan diferentes; un promedio solo del 33\% de los entrevistados, consideró se está haciendo algo o mucho para combatirla, con cifras nacionales distribuidas de la siguiente manera: Uruguay 48\%, Paraguay 24\%, México 22\%, Argentina 21\% y Brasil, nuevamente el peor, con un $19 \%$. Pero vale decir, que todos con cifras desalentadoras.

Esto todavía es más elocuente, no sólo por los resultados expuestos, sino por los datos mostrados también en cuanto a la satisfacción con la democracia, apenas un $37 \%$ en promedio para América Latina, con un $70 \%$ para Uruguay, que repite efectivamente como una de las mejores democracias, Argentina con un 54\%, Paraguay con un 24\%, Brasil con un 21\% y, México, con un vergonzante $19 \%$. Algo se tendrá que hacer.

Tabla 5 - Reporte Latinobarómetro 1995-2015 (Porcentajes promedios)

\begin{tabular}{l|c|c|c|c|c}
\hline \multicolumn{1}{c|}{ Pais/ Concepto } & Brasil & $\begin{array}{c}\text { Argentin } \\
\mathbf{a}\end{array}$ & Mexico & Paraguay & $\begin{array}{c}\text { Urugua } \\
\text { y }\end{array}$ \\
\hline Hay algo o mucho de transparencia & 16 & 34 & 26 & 31 & 61 \\
\hline $\begin{array}{l}\text { Si se está haciendo algo para } \\
\text { combatir la corrupción }\end{array}$ & 19 & 21 & 22 & 24 & 48 \\
\hline Satisfacción con la democracia & 21 & 54 & 19 & 24 & 70 \\
\hline
\end{tabular}

Fuente: Latinobarómetro (1995-2015).

Pero la cuestión es más preocupante, porque la naturaleza de este estudio pretendió dar cuenta de las diferencias democráticas constitucionales en cuanto a los requisitos que Morlino (2008) y Alcántara (2008) señalan como necesarios para las democracias, que como vimos, los contienen en su mayoría. Lo que nos lleva a pensar que: o hay "trampas legales" en las democracias (ya Robert Dahl (2005) cuestionó el funcionamiento Constitucional de los EUA) o, aunque Diamond (2015) se reúse a considerarlo, hay "trampas culturales", que socavan y particularizan la democracia o las democracias. Por lo pronto creemos, habrá que trabajarse constitucionalmente en estas diferencias. 


\section{- Manuel Ángel Rodríguez Edeza é Doutor em Ciências Sociais pela Universidade Autónoma de Sinaloa (UAS). E-mail: maredezasinaloa@hotmail.com.}

- Jorge Giménez é Professor de Ciência Política pela Universidade Federal de Rio Grande do Sul (UFRGS). E-mail: yiyo809@hotmail.com.

- Patricia Rocha é Licenciada en Ciências Sociais pela UFRGS. Email: patriciarocha.rs@hotmail.com.

- Thiago Engelman é Licenciado em Ciências Sociais pela UFRGS. E-mail: thiagoengelman@hotmail.com.

- Leonardo de Alencastro é Licenciado em Ciências Sociais pela UFRGS. E-mail: leonardo.alencastro@ufrgs.br.

\section{Referências}

ALCÁNTARA, Manuel. La calidad del liderazgo político en países andinos. In: Conferencias Magistrales, Partidos Políticos y Calidad de la Democracia. Seminario Internacional, 2008, IFE, México.

ARGENTINA. Constitución Nacional de la Nación Argentina. 1994. Disponível em: $<$ https://www.casarosada.gob.ar/nuestro-pais/constitucion-nacional>. Acesso em: 11 jan. 2017.

BARREDA, Michael. Accountability y calidad de la democracia en América Latina: un análisis comparado. In: Congreso de la Asociación de Estudios Latinoamericanos, 2010, Canadá.

BRASIL. Constitución Política de la República Federativa de Brasil. 1988. Disponível em: <http://www.wipo.int/edocs/lexdocs/laws/es/br/br117es.pdf>. Acesso em: 11 jan. 2017.

CORBETTA, José; PÉREZ-LIÑAN, Aníbal. Calidad de la democracia: un análisis de la trayectoria Argentina, Instituciones y Desarrollo, 2001.

DAHL, Robert. ¿Es democrática la Constitución de los Estados Unidos?, FCE de España, 2005.

DIAMOND, Larry. O espírito da democracia. Atuação. 2015.

DIAMOND, Larry; MORLINO, Leonardo. The quality of democracy: an overview. Journal of democracy, v. 15, n. 4, 2004.

GILAS, Karolina Mónica. Un estudio de la calidad de la democracia mexicana. Biblioteca Jurídica Virtual del Instituto de Investigaciones Jurídicas de la UNAM, México, D.F. 2012. 
86 | Manuel Edeza, Jorge Giménez, Patricia Rocha, Thiago Engelman e Leonardo de Alancaster

GONZÁLEZ, Rodrigo; EDEZA, Manuel Ángel Rodríguez. Constreñimientos a la reforma política en Brasil y México: el rol de la cultura política. In: 10 Congreso Internacional de Ciencia Política, 2016, ABCP, Brasil.

IDH. Índice de Desenvolvimento Humano. 2015. Disponível em: <http://hdr.undp.org/sites/default/files/2015_human_development_report_overview_-_es.pdf>. Acesso em: 20 mar. 2017.

INDICE DE GINI 2014. Disponível em: $<$ http://www.cedlas.econo.unlp.edu.ar/wp/estadisticas/sedlac/estadisticas/\#1496165297107cedda6d3-6c7d>. Acesso em: 20 mar. 2017.

LATINOBARÓMETRO. Informe Latinobarómetro 1995-2015. Disponível em: <http://latinobarómetro.org>. Acesso em: 18 fev. 2017.

LEVINE, Daniel; MOLINA, José Enrique. La calidad de la democracia en América Latina: una visión comparada. América Latina Hoy, n. 45, p. 17-46, 2007.

MÉXICO. Constitución Política de los Estados Unidos Mexicanos. 1917. Disponível em: <http://www.diputados.gob.mx/LeyesBiblio/pdf/1_150917.pdf>. Acesso em: 13 jan. 2017.

MORLINO, Leonardo. Calidad democrática entre líderes y partidos. In: Conferencias Magistrales, Partidos políticos y Calidad de la Democracia, Seminario Internacional, 2008, IFE, México.

PARAGUAY. Constitución Nacional de la República del Paraguay. 1992. Disponível em: $<$ http://www.bacn.gov.py/constitucion-nacional-de-la-republica-del-paraguay>. Acesso em: 15 jan. 2017.

PARAGUAY, Lei n. 5.282, de 18 de setembro de 2014. Instituido Gaceta Oficial de La República de Paraguay. Disponível em: <http://www.hacienda.gov.py/normativa/Ley\%205.2822014\%20De\%20libre\%20acceso\%20ciudadano\%20a\%20la\%20informaci\%C3\%B3n\%20p\%C3\% BAblica\%20y\%20transparencia\%20gubernamental.pdf>. Acesso em: 15 jan. 2017.

PIBpc. Produto Interno Bruto Per Capita. 2015. Disponível em: <https://es.actualitix.com/pais/wld/pib-per-capita-por-pais.php>. Acesso em: 19 mar. 2017.

TOVAR, Jesús. La calidad de la democracia en América Latina. Red de Estudios sobre la Calidad de la Democracia en América Latina, UAEM. 2010.

URUGUAY. Constitución de la República Oriental del Uruguay. 1967. Disponível em: <https://parlamento.gub.uy/documentosyleyes/constitucion>. Acesso em: 13 jan. 2017.

URUGUAY. Lei n. 17.060, 08 de janeiro de 1999. Senado de la República y Cámara de Representantes. Disponível em: <https://legislativo.parlamento.gub.uy/temporales/leytemp1469816.htm>. Acesso em: 13 jan. 2017.

URUGUAY. Lei n. 18.381, 07 de novembro de 2008. Senado de la República y Cámara de Representantes. Disponível em: <https://legislativo.parlamento.gub.uy/temporales/leytemp3759054.htm>. Acesso em: 13 jan. 2017.

Texto recebido em 06 de outubro de 2017. Aprovado em 16 de março de 2018. 